\title{
واقع التعليم المدمج من وجهة نظر \\ المعلمين بمديرية تربية قلقيلية في ضوء بعض المتغيرات
}

$$
\text { سها جلاد، عبير قشوع، لينا أبو حمد، براءة جعيدي }
$$

Sohajallad8@gmail.com, abeer.qashoo7@gmail.com, lina.rabaya11@yahoo.com, barahayazeed@gmail.com 


\title{
و اقع التعليم المدمج من وجهة نظر المعلمين بمديرية تربية قلقيلية في ضوء بعض المتغيرات
}

\author{
سها جلاد، عبير قشوع²، لينا أبو حمد³، براءة جعيدي4 \\ إدارة تربوية- جامعة النجاح الوطنية- فلسطين
}

1Sohajallad8@gmail.com, 2abeer.qashoo7@gmail.com, 33lina.rabaya11@yahoo.com, ${ }^{4}$ barahayazeed@gmail.com

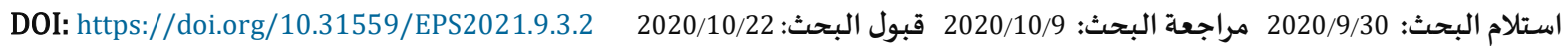

هدفت الدراسـة التعرف إلى واقع التعليم المدمج من وجهة نظر المعلمين بمديرية تربية قلقيلية في ضوء بعض المتغيرات، والوقوف على تحديات التعليم المدمج من وجهة نظر مشرفي التربية والتعليم بمديرية تربية قلقيلية وسبل مواجهتها، ولتحقيق أهد اف الدراسـة تم استخدام أسلوب المزج بين المنهج الوصفي والنوعي كمنهج للدراسة، وتكونت أداة الدراسة من استبانة مكونة من (33) فقرة، موزعة على(4) محاور، تم تطبيقها على(143) معلماً ومعلممة، بالإضافة إلى إجراء مقابلات نوعية مع (5) من مشرفي التربية والتعليم بمديرية

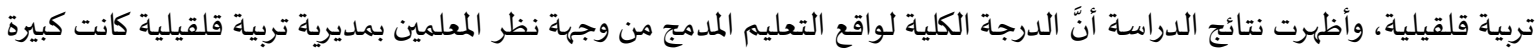
وبمتوسط حسابي(3.84)، وبنسبة مئوية (75.8\%)، وقد حصل مجال تحديات التعليم المدمج على الترتيب الأول بمتوسط حسابي

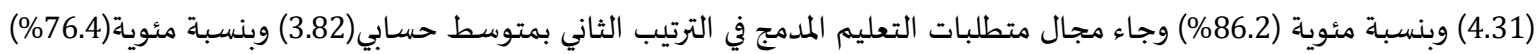
وجاء في الترتيب الثالث مجال المعرفة بمفهوم التعليم المدمج، بمتوسط حسابي(3.69) وبنسبة مئوية (73.8\%)، وحصل مجال أهمية

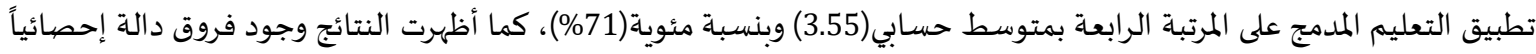
على الدرجة الكلية لواقع التعليم المدمج من وجهة نظر المعلمين تعزى لمتغير الجنس، ولصيالح الذكور، ووجود فروق دالة إحصيائياً على إلى

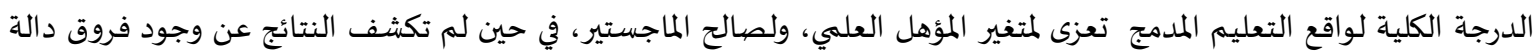
إحصائياً تعزى لمتغيري سنوات الخدمة، أو مجال التخصص، وأظهرت نتائج مقابلات المشرفين التربويين أنَّ (80\%) من تحديات تطبيق

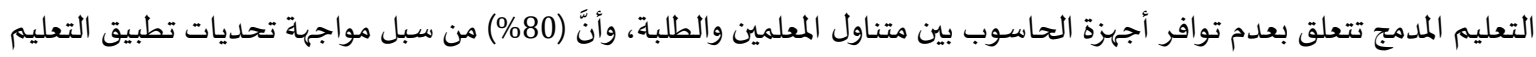

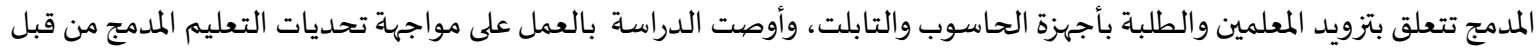

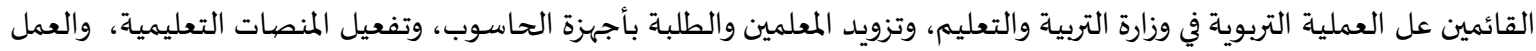

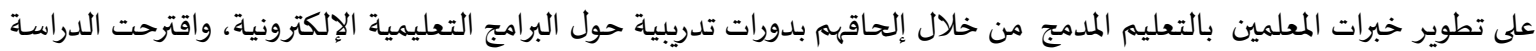

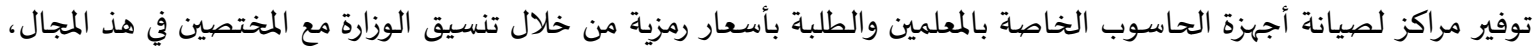

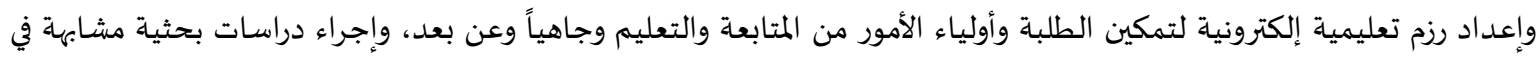
مديريات مختلفة من فلسطين.

الكلمات المفتاحية: التعليم المدمج؛ تحديات تطبيق التعليم المدمج؛ قلقيلية. 
يعد التعليم جزء لا يتجزأ من تطور المجتمع، يتأثر كفيره من المجالات بالتغيرات المتسارعة وتقدم التكنولوجيا، وهذا ما يدفع بالمؤسسات

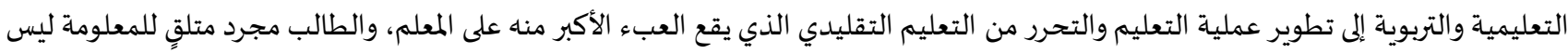

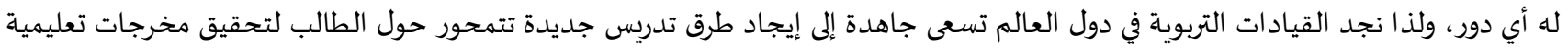

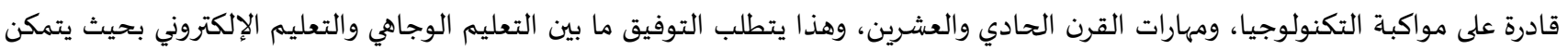

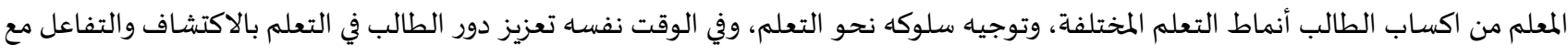

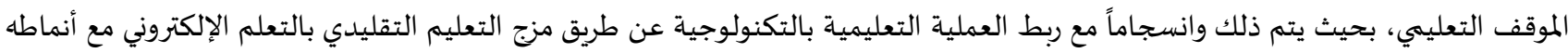

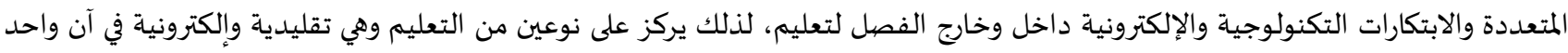

(أصلان، 2015).

ويؤكد صالح (2005) على أن بيئات التعلم الإلكتروني هي عبارة عن نظام يتضمن تقديم محتوى تعليهي جيد، وإعداد واجهاه تفاعل مناسبة

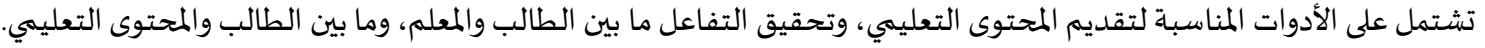

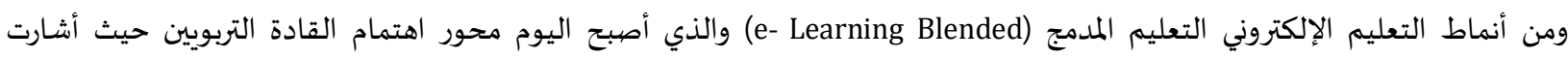

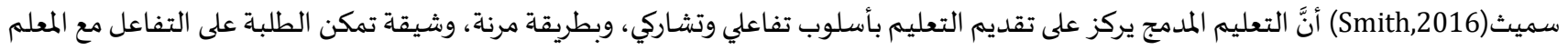
والمحتوى التعليمي.

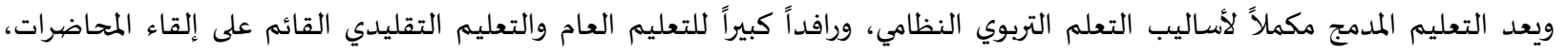

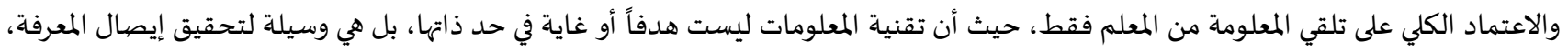

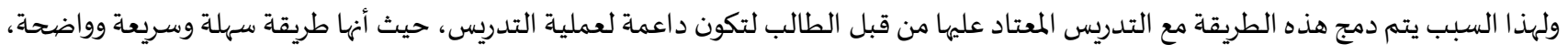

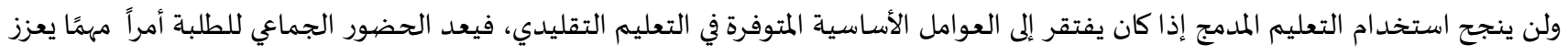

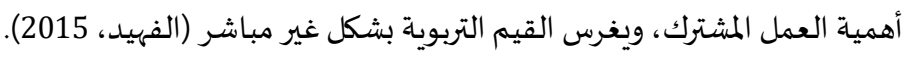

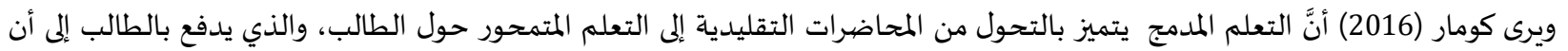

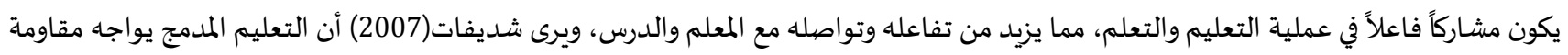

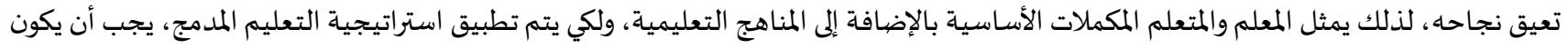

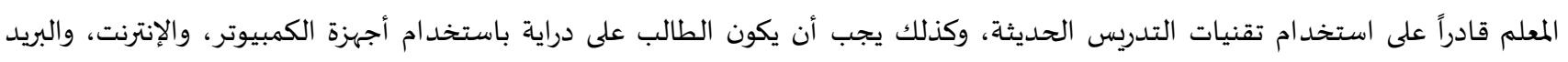

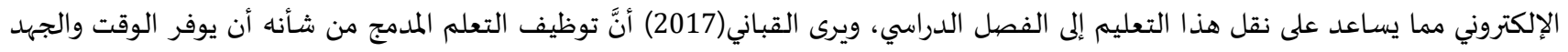

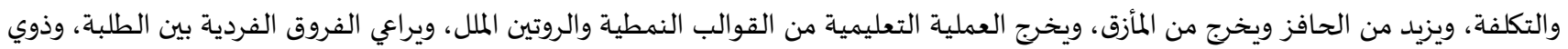

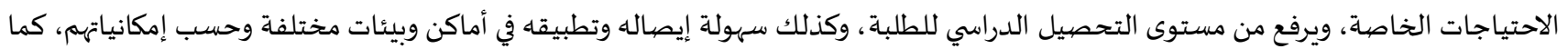

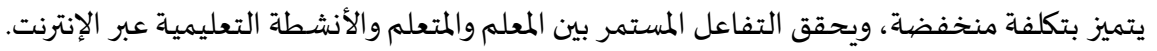

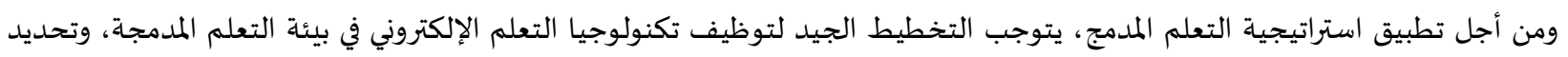

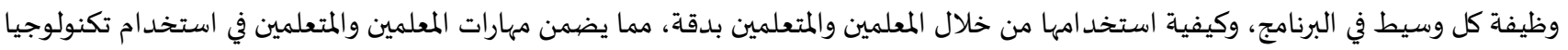

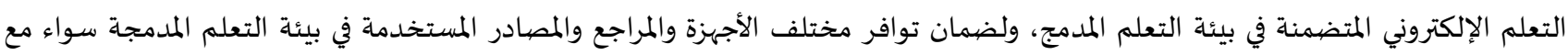

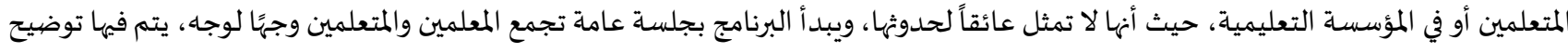

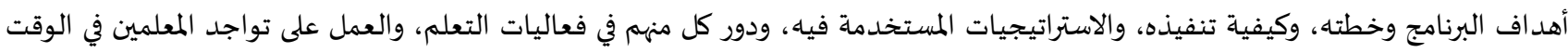

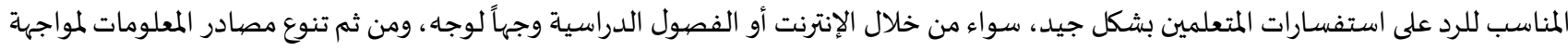
الفروق الفردية بين المتعلمين (عبد العاطي والسيد، 2009).

الدراسات السابقة:

وقد تناولت العديد من الدراسات البحثية التعليم المدمج: هقد أجرى كل من سشميد وميزر وسكوب( Schmid,Melzer\& Schoop,2020) دراسة هدفت التعرف إلى متطلبات التعلم الفعال لتحفيز

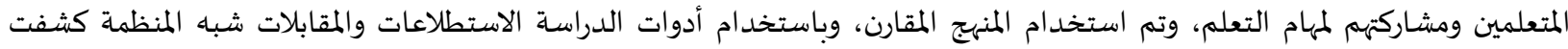

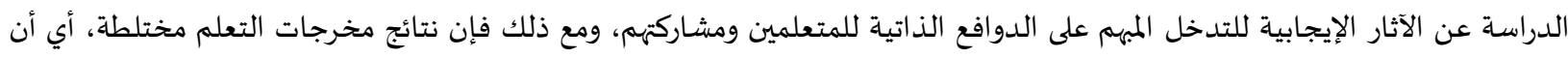


المتعلمين الذين يستخدمون النظام المحسَّن ينظرون إلى أنفسهم على أههم أكثر كفاءة، لكن المقاييس الموضوعية لنتائج التعلم تكشف عن نتائج أسوأ من المجموعة غير المصنفة.

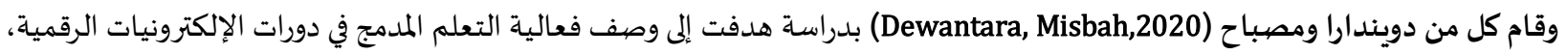

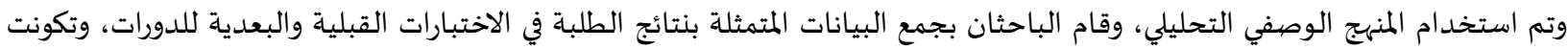

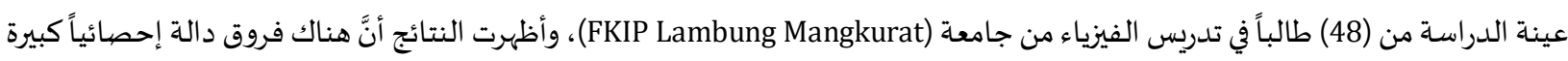

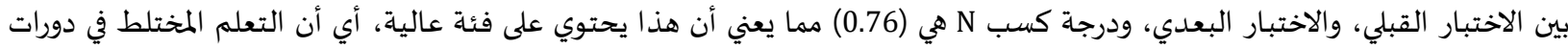
الإلكترونيات الرقمية فعال في تحسين نتائج تعلم الطلبة. كما وقام ديوندارا (Dewantara,2020) بدراسة هدفت إلى تحليل جودة تنفيذ التعلم الممزوج في تعلم الإلكترونيات التناظرية من حيث جوانب التباني

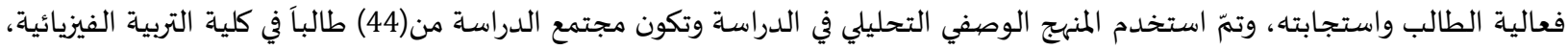

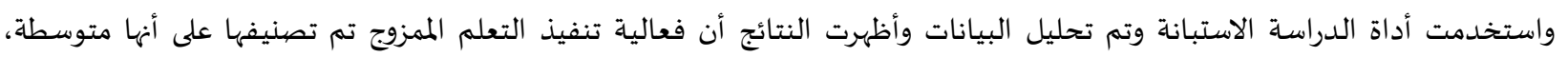
واستجابة الطالب للتعلم من خلال التعلم الممزوج كانت جيدة، أي أن جودة تنفيذ التعلم الممزوج في تعلم الإلكترونيات التناظرية لها فعالية متوسطة.

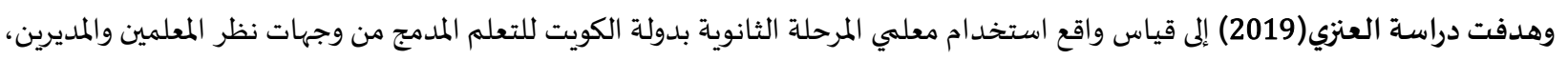

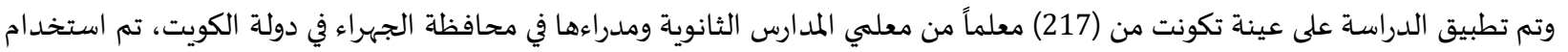

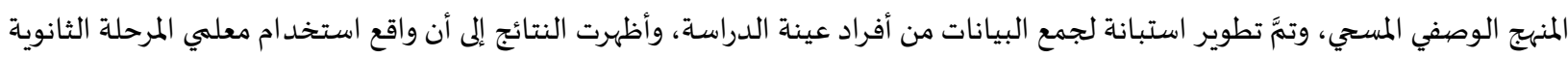

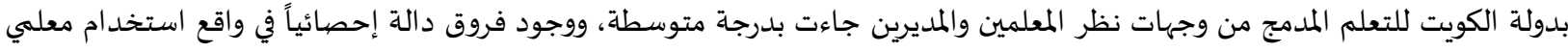

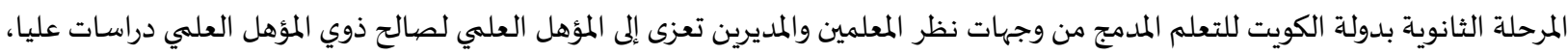

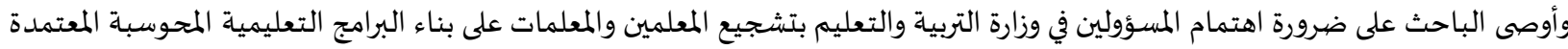
على التعلم المدمج، وإعادة النظر في البرامج والمناهج المدروسية واستراتيجيات فن فئفيذها.

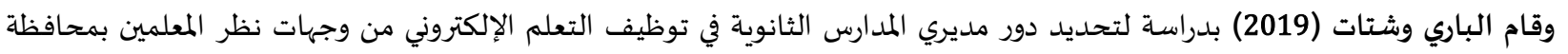

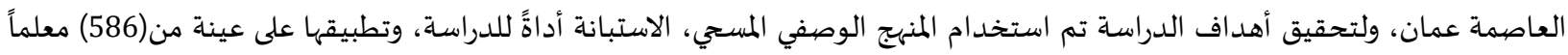

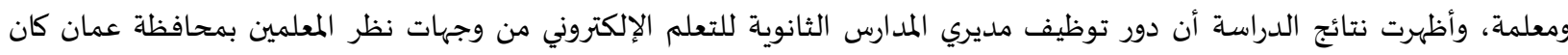

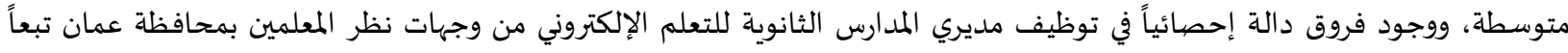

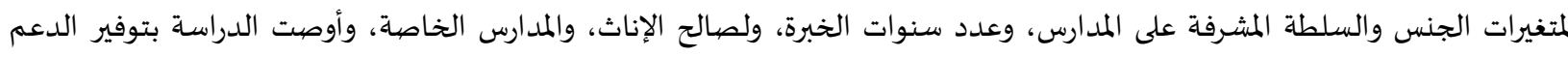

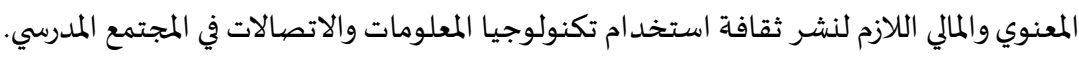

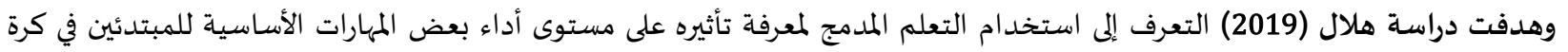

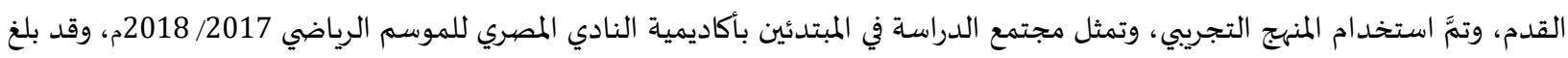

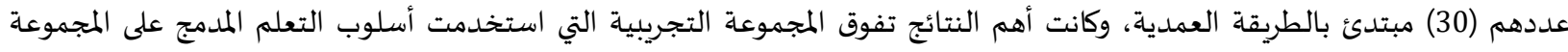

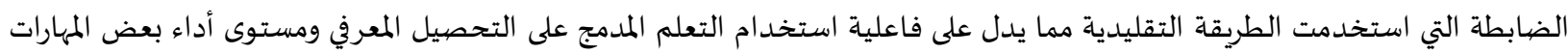
الأساسية للمبتدئين في كرة القدم.

وقام الرحيهي (2018) بدراسة هدفت التعرف إلى مدى فعالية التعليم المدمج في تطوير السمات الشخصية والمهارات الوظيفية لدى خريجي

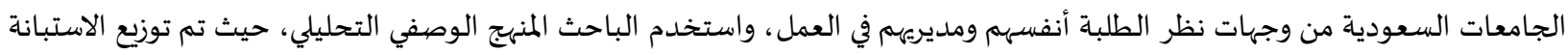

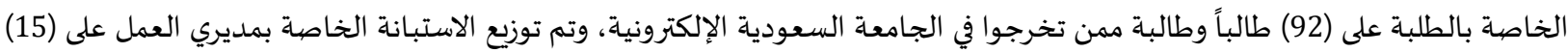

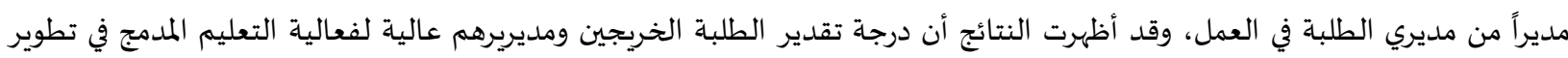
المهارات الوظيفية والسمات الشخصية، كما أشارت النتائج على وجود فروق دالة إحصائياً في تقييم فعالية التعليم المددمج تعزى لاختلاف الدرجية

العلمية.

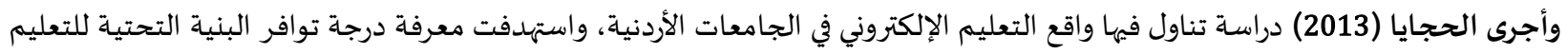

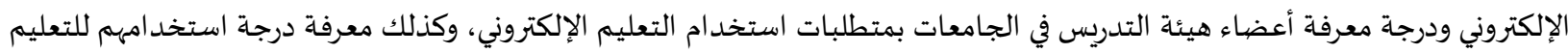

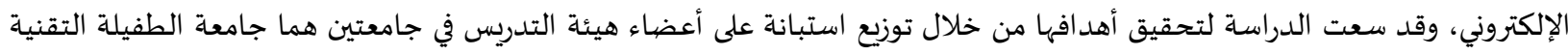

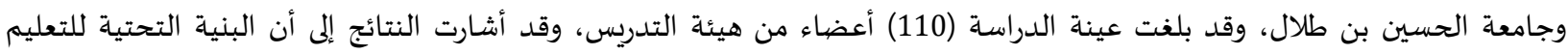

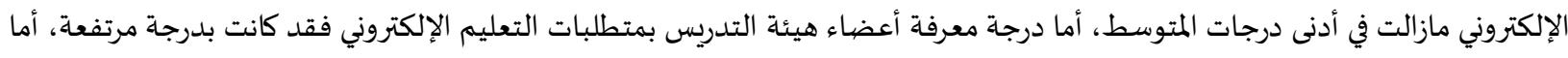


درجة ممارسة أعضاء هيئة التدريس في الجامعات الأردنية للتعليم الإلكتروني فقد كانت بدرجة متوسطة، وقد أوصت الدراسة بزيادة الدعم

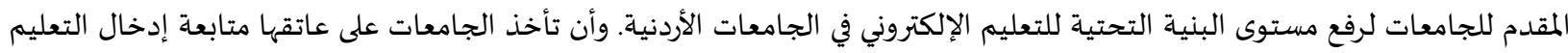
الإلكتروني في برامجها ومتابعة تطبيقه من قبل أعضاء هيئة التدريس، وأن تأخذ الجامعات بمطالب التعليم الإلكتروني عند اختيارها أعضياء هيئة التدريس، وإعداد برامج موجهة إلى أعضاء هيئة التدريس لتطوير خبراتهم وتدريبهم على ممارسة التعليم الإلكتروني. هدفت دراسـة عوض (2003) إلى الكشف عن معدل امتلاك أعضاء هيئة التدريس في كليات التربية بالجامعات الأردنية للكفايات التكنولوجية من وجهة نظرهم، ودلت النتائج إلى أن أهم الكفايات التي توفرت لدى أعضاء هيئة التدريس هي: تحديد كيفية تعلم الطلبة، وتحديد

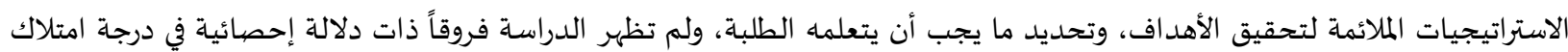
الكفايات التكنولوجية تعزى لمتغيري الجامعة والتخصص، وظهرت فروق ذات دلالة إحصائية تعزى إلى متغير الخبرة ولصالح أصحاب الخبرة

الأقل من خمس سنوات.

وأجرى فانفوسن (vanfossen, 2001) دراسة هدفت التعرف إلى مستوى امتلاك معلمي المرحلة الثانوية لكفايات التعليم الإلكتروني في ولاية

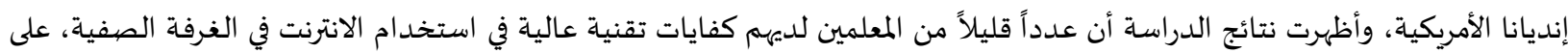

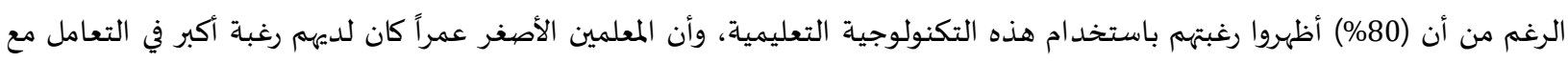

الإنترنت، كذلك المعلمين الأقل خبرة، وأظهرت النتائج وجود نقص حاد في التدريب على استخد ام الانترنت، وتوظيفه في الغرفة الصفية.

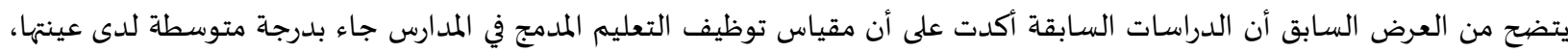

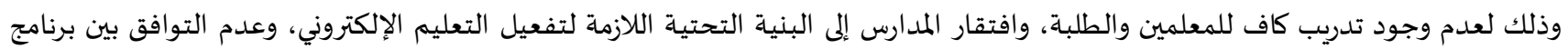
التدريس الواقعي والبرنامج الإلكتروني.

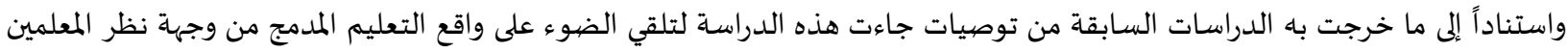
بمديرية تربية قلقيلية في ضوء بعض المتغيرات في فلسطين والتعرف إلى تحديات استخدام هذه التقنيات في العملية التعليمية.

مشكلة الدراسـة: على الرغم من التطورات الكبيرة في مجال التربية والتعليم من حيث توظيف تكنولوجيا المعلومات في العملية التعليمية، إلا أن كثير من المدارس

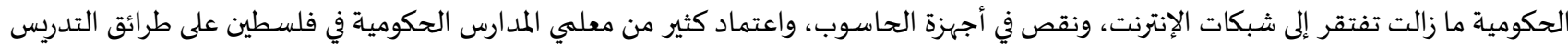

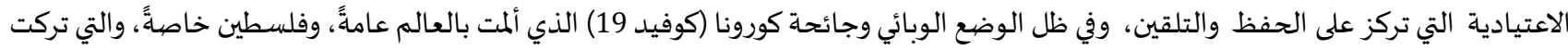

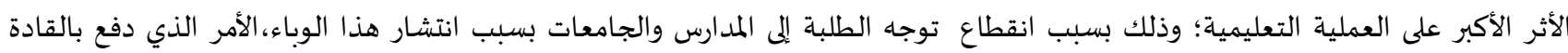

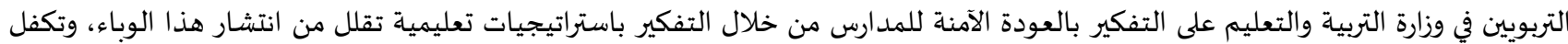

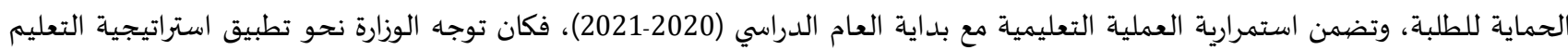
المدمج القائم على الدمج بين التعليم الوجاهي والتعليم الإلكتروني، وشرعت في سبيل ذلك على تدريب المعلمين والمعلمات على توظيف هذه الاستراتيجية

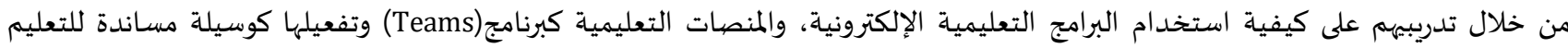

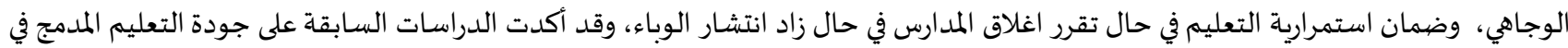
زيادة تفاعل الطلبة وزيادة دافعيتهم نحو التعليم كدراسة دويندارا ومصبباح (Dewantara, Misbah,2020) التي توصلت إلى فعالية التعلم المدمج في

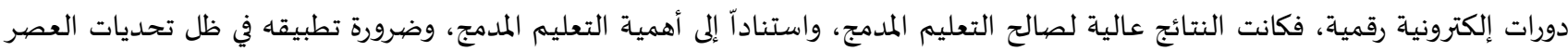
والظروف التي يعيشها العالم بشكل عام، وفلسطين بشكل خاص، وانطلاقاً من نتائج الدراسات السابقة التي أوصت بتطبيق التعليم المدمج، فقد تحددت مشكلة الدراسة في: واقع التعليم المدمج من وجهة نظر المعلمين بمديرية تربية قلقيلية.

أسئلة الدراسـة: - n

سعت الدراسـة للإجابة عن الأسئلة التالية:

1. ماواقع التعليم المدمج من وجهاة نظر المعلمين بمديرية تربية قلقيلية؟

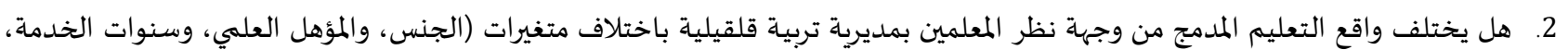

ومجال التخصص)

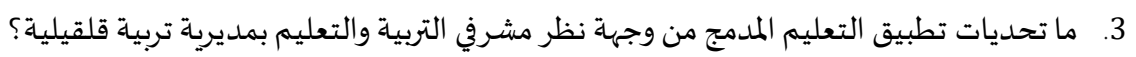

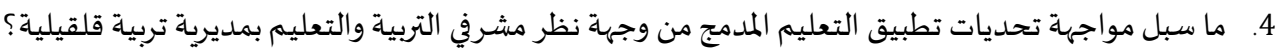




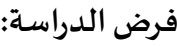

سعت الدراسة الحالية إلى فحص الفرض الصفري التالي:

لا توجد فروق ذات دلالة إحصيائية عند مستوى الدلالة (X=0.05) في و اقع التعليم المدمج من وجهة نظر المعلمين بمديرية تربية قلقيلية تعزى لمتغيرات (الجنس، والمؤهل العلمي، وسنوات الخدمة، ومجال التخصص).

أهداف الدراسـة:

سعت هذه الدراسة إلى تحقيق الأهد اف التالية:

1. التعرف إلى واقع التعليم المدمج من وجهاة نظر المعلميق الاهدين بمديرية تربية قلقيلية.

2. تحديد طبيعة الفروق في واقع التعليم المدمج بمديرية تربية قلقيلية من وجهة نظر المعلمين والمعلمات تبعاً لمتغير الجنس، والمؤهل العلمي،

$$
\text { وسنوات الخدمة، والتخصص. تحسد. }
$$

3. التعرف إلى تحديات تطبيق التعليم المدمج من وجهة نظر مشرفي التربية والتعليم بمديرية تربية قلقيلية. 4. التعرف إلى سبل مواجهاة تحديات تطبيق التعليم المدمج من وجهة نظر مشرفي التربية والتعليم بمديرية تربية قلقيلية.

$$
\text { أهمية الدراسـة: }
$$

الأهمية النظرية: تستمد هذه الدراسة أهميتها النظرية من:

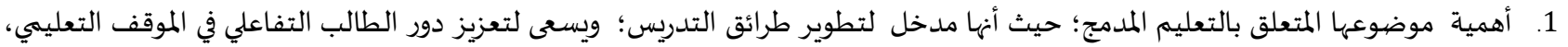

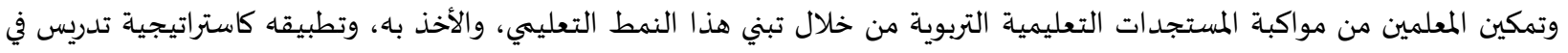
المدارس الحكومية. 2. ت تعد من الدراسات البحثية الأولى التي تناولت واقع التعليم المدمج من وجهة نظر المعلمين بمديرية قلقيلية حسب علم الباحثين.

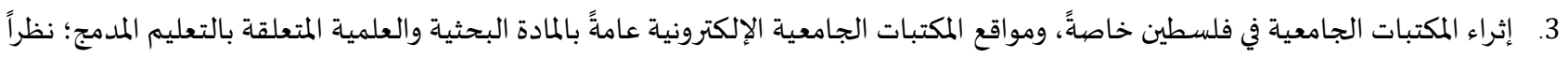
لقلة الدراسات والأبحاث والمراجع التي تناولت هذا الموضوع في فلسطين. الأهمية التطبيقية: تبرز الأهمية التطبيقية للدراسة في: 1. توجياء أنظار المهتمين من متخذي القرار في وزارة التربية والتعليم لأهمية التعليم المدمج والتعرف إلى واقع ممارسته في الميدان، والاستفادة من

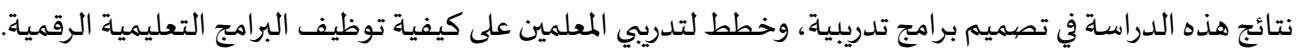
2.

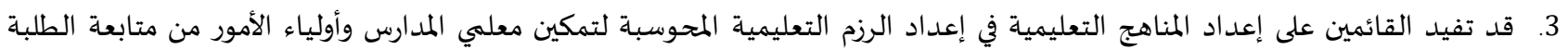
وتحقيق التوازن بين متطلبات التعليم الوجاهي والتعليم عن بعد.

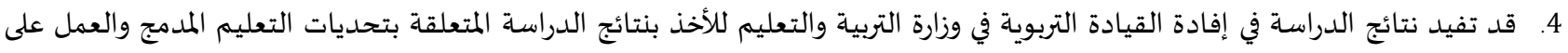
مواجهة هذه التحديات. حدود الدراسـة: تتحدد الدراسة الحالية بموضوعها المتمثل في واقع التعليم المدمج من وجهة نظر المعلمين بمديرية تربية قلقيلية، وبعينتها المكونة من (143) من

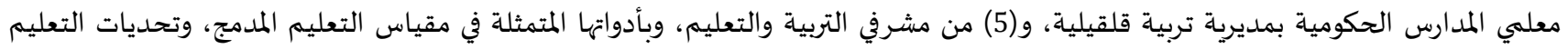

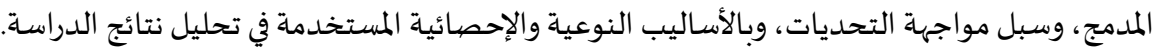

$$
\text { مصطلحات الدراسة: }
$$

التعليم المدمج: هو استخدام وسائل الاتصال المختلفة، بما في ذلك الاجتماع المباشر، والتعلم الذاتي والاتصال على الإنترنت، فهو يمزج بين التعليم

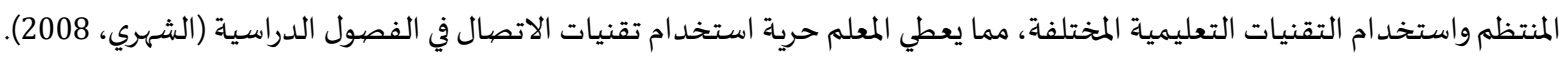
ويُعرف إجر ائياً: الوقوف على واقع الدمج بين التعليم الوجاهي والتعليم عن بعد الإلكتروني وتطبيقه في المدارس الحكومية بمديرية تربية قلقيلية من

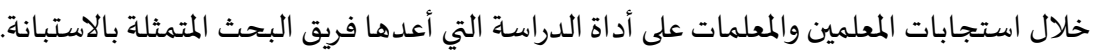

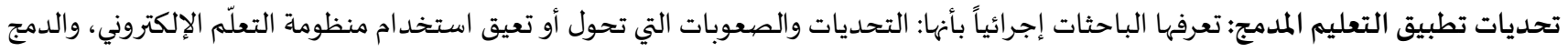
بين التعليم الوجاهي والتعليم الإلكتروني وتطبيقه في مديرية تربية قلقيلية، وتؤثر سلبياً في استخداسيا لهريا ونتائجها. 
| (إجراءات الدراسة:

منهج الدراسة:

استخدمت الدراسة أسلوب الدمج بين المنهج الوصفي بصورته التحليلية المتمثلة بجمع البيانات وتحليلها، والمنهج النوعي من خلال الاستماع إلى الماتيات آراء المبحوثين، ووصفها، وحساب نسبة التكرارات، وقد تناول موضوع الدراسة" واقع التعليم المدمج من وجهة نظر المعلمين بمديرية تربية قلقيلية في ضوء بعض المتغيرات".

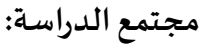
تكون مجتمع الدراسة من جميع المعلمين والمعلمات، والبالغ عددهم (621) معلماً ومعلمة في المدارس الحكومية الأساسية في مديرية التربية والتعليم في قلقيلية. عينة الدراسة: تكونت عينة الدراسة من (143) معلماً ومعلمة تم اختيارهم بشكل عشوائي من المدارس الحكومية في مديرية قلقيلية، وجدول (1) يبين توزيع عينة الدراسة من المعلمين والمعلمات وفقاً لمتغيرات الدراسة.

\begin{tabular}{|c|c|c|c|}
\hline النسبة المئوية \% & العدد & مستويات المتغير & المتغير \\
\hline 34.3 & 49 & ذكر & الجنس \\
\hline 65.7 & 94 & أنثى & \\
\hline 100.0 & 143 & المجموع & \\
\hline 9.1 & 13 & دبلوم & المؤهل العلمي \\
\hline 74.1 & 106 & بكالوريوس & \\
\hline 16.8 & 24 & ماجستير فأعلى & \\
\hline 100.0 & 143 & المجموع & \\
\hline 23.8 & 34 & اقل من 5 سنوات & سنوات الخدمة \\
\hline 28.7 & 41 & من 5-10 سنوات & \\
\hline 47.6 & 68 & أكثر من 10 سنوات & \\
\hline 100.0 & 143 & المجموع & \\
\hline 30.8 & 44 & علمية & مجال التخصص \\
\hline 65.0 & 93 & إنسانية & \\
\hline 4.2 & 6 & مني-صناعي & \\
\hline 100.0 & 143 & المجموع & \\
\hline
\end{tabular}

كما تمَّ إجراء مقابلة مع (5) من مشرفي التربية والتعليم بمديرية قلقيلية بهدف معرفة التحديات التي قد تواجه تطبيق التعليم المدمج في المدارس الحكومية في مديرية قلقيلية، وسبل مواجهة تلك التحديات. أداتي الدراسة: استخدمت الدراسة المقاييس الآتية: أولاً: أداة الاستبانة لفحص و اقع التعليم المدمج: وصف المقياس: تم إعداد المقياس بعد الرجوع للأدب التربوي والدراسات السابقة ذات العلاقة ومنها دراسة هلال(2019)، ودراسة العنزي(2019)، وتكون المقياس في صورته النهائية من (33) فقرة بعد التحكيم، موزعة على أربع مجالات، وهي:

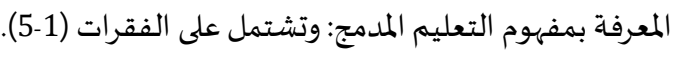
أهمية تطبيق التعليم المدمج: وتشتمل على الفقرات (6-13).

متطلبات التعليم المدمج: وتشتمل على الفقرات (12-22). تحديات التعليم المدمج : وتشتمل على الفقرات (23-33). 
وقد تمَّ تصميم المقياس بناءً على مقياس ليكرت الخماسي والذي يبدأ بموافق بشدة (5) درجات، وموافق(4) درجات، ومحايد(3) درجات،

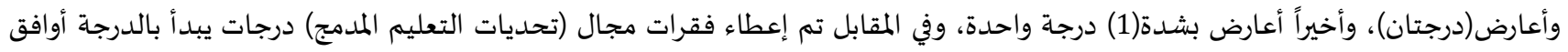

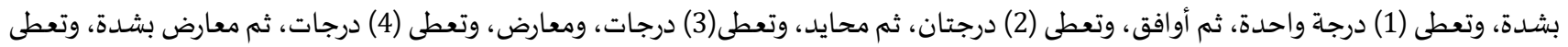

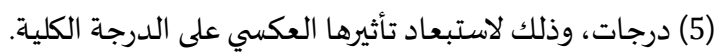

صهدق المقياس:

تم التحقق من صدق المقياس بالطرق الآتية: 1. 1 صددق المحكمين: تم عرض المقياس على (5) من المتخصصين في المناهج والإدارة التربوية من كليات التربية في الجامعات الفلسطينية، وذلك للحكم على مدى صلاحيتاه للتطبيق، وتعديل ما يرونه مناسبًا، وقد اتفق المحكمون على إضافة تعديل المتيل بعض الفقرات، فيما اتفقوا على صلاحية باقي الفقرات للتطبيق،

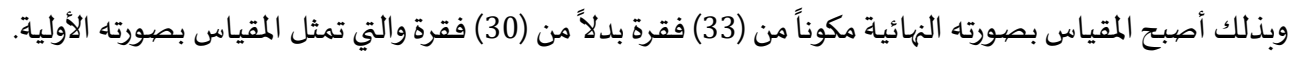
2. 2 الصيدق البنائي: تم تطبيق الأداة على عينة استطلاعية عددها (30) من المعلمين من خارج عينة الدراسة، وتم إيجاد معاملات الارتباط بين درجة كل مجال مع الدرجة الكلية للأداة، والجدول (2) يوضح ذلك: تلكئل

\begin{tabular}{|c|c|c|}
\hline ق قيمة الدلالة & معامل الارتباط & 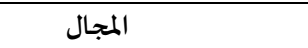 \\
\hline 0.000 & ${ }^{* *} .954$ & المعرفة بمفهوم التعليم المدممج \\
\hline 0.000 & $* * .951$ & أهمية تطبيق التعليم المدمج \\
\hline 0.000 & $* * .885$ & متطلبات التعليم المدمجج \\
\hline 0.048 & $* .364$ & تحديات التعليم المدمج \\
\hline
\end{tabular}

يتضح من الجدول (2) أن معاملات الارتباط مرتفعة ودالة، مما يؤكد على صبدق المقياس، وصلاحيته للتطبيق. ثبات المقياس:

للتحقق من مدى ثبات المقياس، تم حساب ثبات المقياس باستخدام معامل الثبات كرونباخ ألفا، وكانت قيم الثبات كما هي موضحة في الجدول

جدول (3): يبين الجدول معامل الثبات للدرجة الكلية و أبعاد مقياس و اقع التعليم المدمجج من وجهة نظر المعلمين

\begin{tabular}{|c|c|c|}
\hline معامل الثبات & المجال & رقم المجال \\
\hline 0.832 & المعرفة بمفهوم التعليم المدمجج & الأول \\
\hline 0.912 & أهمية تطبيق التعليم المدمجج & الثاني \\
\hline 0.904 & متطلبات التعليم المدمج & 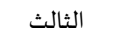 \\
\hline 0.887 & تحديات التعليم المدمج & 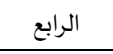 \\
\hline 0.932 & لي لمحور الاستبانة & \\
\hline
\end{tabular}

يتضح من الجدول (3) أنَّ معاملات الثبات لمجالات المقياس لمحور واقع التعليم المدمج من وجهة نظر المعلمين بمديرية تربية قلقيلية تراوحت بين(0.832-0.912)، ومعامل الثبات الكلي للاستبانة(0.932) وجميعها معاملات ثبات عالية تؤكد على صلاحية المقياس للتطبيق. ثانيا: المقابلة لفحص تحديات التعليم المدمجج اعتمد الباحثين على المقابلة شبه المنتظمة، وطرح الأسئلة على مشرفي التربية والتعليم بمديرية قلقيلية، والبالغ عددهم (5) مشرفين تربويين لتحقيق أهداف الدراسة وجمع المعلومات التي تدعم كل ما ورد في الاستبانة. صددق المقياس: تم التحقق من الصدق الظاهري للمقياس من خلال عرض أسئلة المقابلة على بعض محكمي الاستبانة من هيئة أعضاء التدريس في جامعة

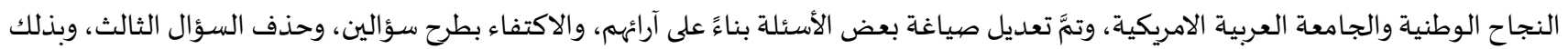
يكون قد تحقق الصدق الظاهري لأداة المقابلة. 
نتائج الدراسة ومناقشتها:

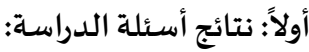

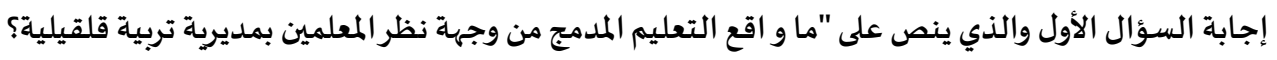

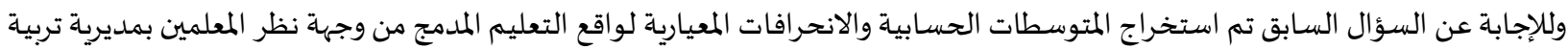

قلقيلية، وجدول (4) يوضح ذلك:

جدول (4): المتوسطات الحسابية والانحر افات المعيارية لو اقع التعليم المدمج من وجهة نظر المعلمين

رقم المجال

\begin{tabular}{|c|c|c|c|c|c|}
\hline النسبة & الدرجة & الانحراف & المتوسط الحسابي & & \\
\hline$\% 73.8$ & كبيرة & 0.74 & 3.69 & المعرفة بمفهوم التعليم المدمج & 1 \\
\hline$\% 71$ & 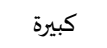 & 0.79 & 3.55 & أهمية تطبيق التعليم المدمجج & 2 \\
\hline$\% 76.4$ & 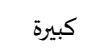 & 0.69 & 3.82 & متطلبات التعليم المدمج & 3 \\
\hline$\% 86.2$ & كبيرة جداً & 0.53 & 4.31 & تحديات التعليم المدمجج & 4 \\
\hline \%75.8 & كبيرة & 0.68 & 3.84 & الدرجة الكلية & \\
\hline
\end{tabular}

يتضح من جدول(4) أنَّ واقع التعليم المددمج من وجهة نظر المعلمين بمديرية تربية قلقيلية جاء بدرجة كبيرة؛ حيث بلغ المتوسط الحسابي للدرجة الكلية (3.84) ،وبنسبة مئوية قدرها (75.8\%) من المعلمين، كما جاء متوسط استجابات المعلمين في المجالات الأولى والثانية، والثالثة كبيرة، بينما المجالئ المالئ

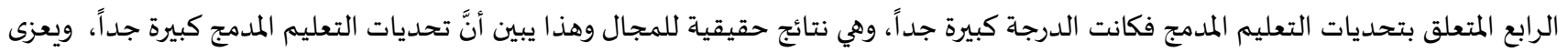

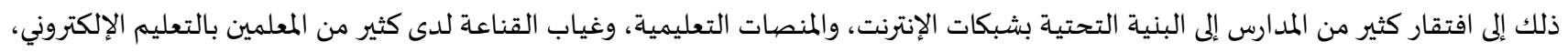

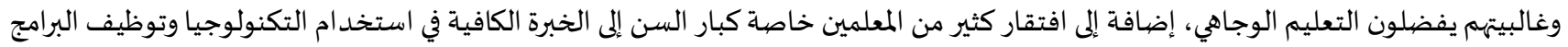

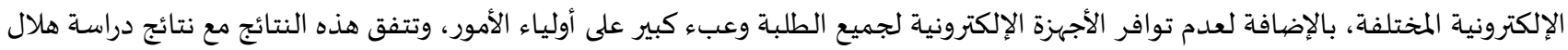

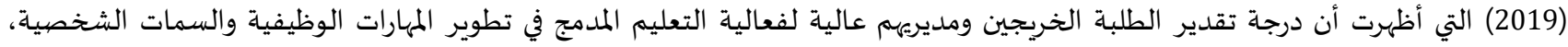

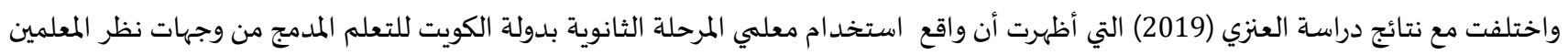
والمديرين جاءت بدرجة متوسطة.

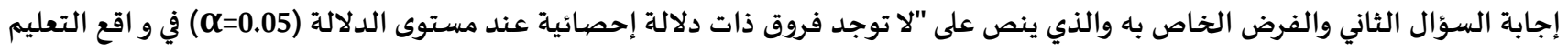

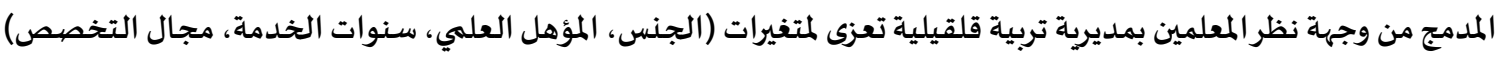

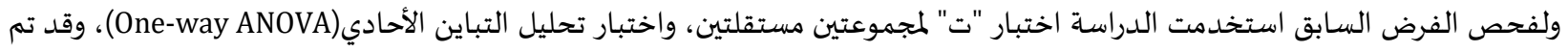
عرض نتائج كل متغير على حدة على النحو التالي:

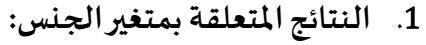

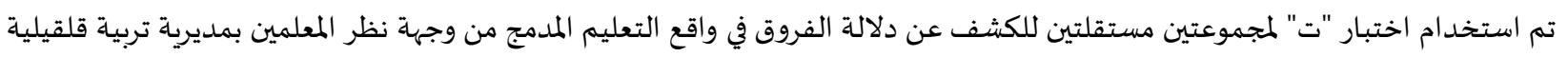
في ضوء متغير الجنس (ذكر، أنثى)، وكانت النتائج كما هي موضحاة في جدول معندان (5): جدول (5): نتائج اختبار"ت" لدلالة الفروق في و اقع التعليم المدمج من وجهة نظرعينة الدراسة تبعاً لمتغير الجنس

\begin{tabular}{|c|c|c|c|c|c|c|}
\hline \multirow{2}{*}{ 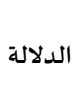 } & \multirow{2}{*}{ قيمة (ت) } & \multicolumn{2}{|c|}{ أنثى (ن =94) } & \multicolumn{2}{|c|}{ ذكر (ن=49) } & \multirow{2}{*}{ 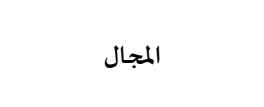 } \\
\hline & & الانحراف & المتوسط & الانحراف & المتوسط & \\
\hline$* 0.024$ & 2.302 & 0.70 & 3.59 & 0.77 & 3.89 & المعرفة بمفهوم التعليم المدمج \\
\hline$* 0.043$ & 2.048 & 0.78 & 3.46 & 0.77 & 3.73 & أهمية تطبيق التعليم المدمج \\
\hline 0.215 & 1.249 & 0.66 & 3.76 & 0.75 & 3.92 & متطلبات التعليم المدممج \\
\hline 0.121 & 1.569 & 0.48 & 1.64 & 0.62 & 1.80 & تحديات التعليم المدمدج \\
\hline$* 0.019$ & 2396 & 0.52 & 3.11 & 0.54 & 3.34 & الدرجة الكلية \\
\hline
\end{tabular}

يتضح من نتائج جدول (5) عدم وجود فروق دالة إحصائياً عند مستوى الدلالة (م=0.05) بين واقع التعليم المددمج من وجهة نظر المعلمين

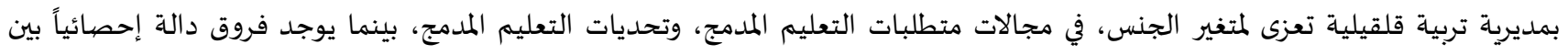

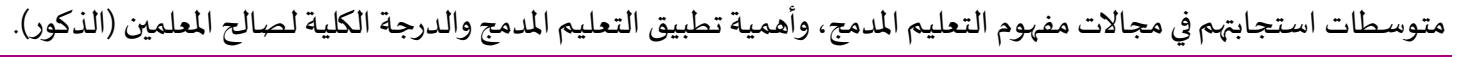


وتُعزى هذه النتيجة إلى تشابه وجهات نظر المعلمين والمعلمات في تقديرهم لمتطلبات التعليم المدمج وتحدياته، لكونه يتطلب توفير أجهزة حاسوب

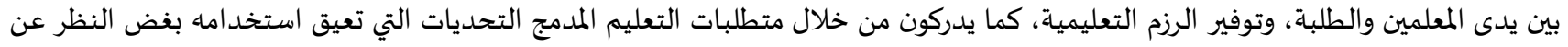

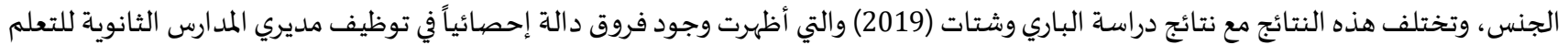
الإلكتروني من وجهات نظر المعلمين بمحافظة عما تبعاً لمتغير الجنس، ولصعالح الإناث.

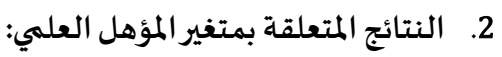
تم استخدام تحليل التباين الأحادي(One-way ANOVA)، للكشف عن دلالة الفروق في واقع التعليم المدمج من وجهة نظر المعلمين بمديرية تربية قلقيلية في ضوء المؤهل العلمي (دبلوم، بكالوريوس، ماجستير فأعلى)، وكانت النتائج كما في جدول (6) دلائ.

\begin{tabular}{|c|c|c|c|c|c|c|}
\hline الإحصائية & قيمة(ف) & متوسط المربعات & درجات الحرية & مجموع المربعات & مصدر التباين & المجالات \\
\hline \multirow[t]{3}{*}{0.082} & 2.553 & 1.368 & 2 & 2.735 & بين المجموعات & \\
\hline & & 0.536 & 140 & 75.009 & داخل المجموعات & المعرفة بمفهوم التعليم \\
\hline & & & 142 & 77.744 & المجموع & المدمج \\
\hline \multirow[t]{3}{*}{$* 0.017$} & 4.222 & 2.494 & 2 & 4.989 & بين المجموعات & \\
\hline & & 0.591 & 140 & 82.709 & داخل المجموعات & أهمية تطبيق التعليم \\
\hline & & & 142 & 87.698 & المجموع & المدمج \\
\hline \multirow[t]{3}{*}{0.189} & 1.683 & 0.797 & 2 & 1.594 & بين المجموعات & \\
\hline & & 0.474 & 140 & 66.299 & داخل المجموعات & متطلبات التعليم المددمج \\
\hline & & & 142 & 67.893 & المجموع & \\
\hline \multirow[t]{3}{*}{0.518} & 0.660 & 0.189 & 2 & 0.379 & بين المجموعات & \\
\hline & & 0.287 & 140 & 40.180 & داخل المجمموعات & تحديات التعليم المدمجج \\
\hline & & & 142 & 40.559 & المجموع & \\
\hline \multirow[t]{3}{*}{${ }^{*} 0.041$} & 3.272 & 0.915 & 2 & 1.830 & بين المجموعات & \\
\hline & & 0.280 & 140 & 39.152 & داخل المجمموعات & الدرجة الكلية \\
\hline & & & 142 & 40.982 & المجموع & \\
\hline
\end{tabular}

يتضح من الجدول (6) عدم وجود فروق دالة إحصائياً عند مستوى الدلالة (م=0.05) بين واقع التعليم المدمج من وجهة نظر المعلمين بمديرية تربية قلقيلية تعزى لمتغير المؤهل العلمي، في مجالات مفهوم التعليم المدمج، ومتطلبات التعليم المدمج، وتحديات التعليم المدمجج، بينما يوجد فروق دالة

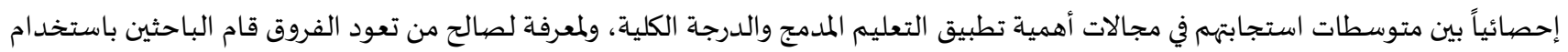

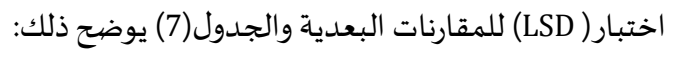

\begin{tabular}{|c|c|c|c|c|}
\hline ماجستير فأعلى & بكالوريوس & دبلوم & المؤهل العلمي & المجال \\
\hline-0.10296 & 0.35586 & & مبلوم & \\
\hline \multirow[t]{2}{*}{$*_{-} .45882-$} & & -0.35586 & بكالوريوس & أهمية تطبيق التعليم المدمجج \\
\hline & $.45882^{*}$ & 0.10296 & ماجستير فأعلى & \\
\hline-0.10342 & 0.18480 & & دبلوم & \\
\hline \multirow[t]{2}{*}{$*_{-.28822-}$} & & -0.18480 & بكالوريوس & الدرجة الكلية \\
\hline & $.28822^{*}$ & 0.10342 & ماجستير فأعلى & \\
\hline
\end{tabular}

يشير الجدول (7) إلى وجود فروق دالة إحصائياً عند مستوى الدلالة (م=0.05) في الدرجة الكلية و مجال أهمية تطبيق التعليم المدمج بين

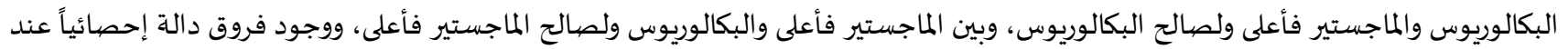

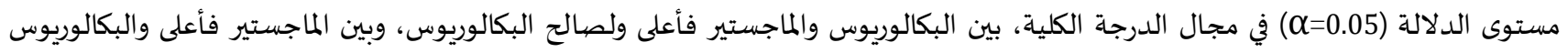

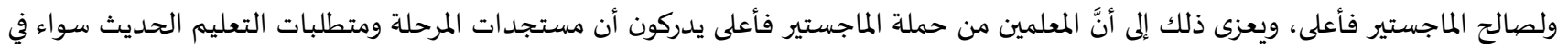
المدارس، أو الجامعات يتطلب توظيف التعليم الإلكتروني، وتوظيف التكنولوجيا في العملية التعليمية، وكثير من برامج الدراسات العليا تدعم التعليم 
المدمج، ولذلك حملة الماجستير فأعلى يدركون أهمية تطبيق التعليم المدمج، وتتفق هذه النتائج مع نتائج دراسة العنزي(2019) والتي أظهرت وجود فروق تعزى للمؤهل العلمي لصالح الدراسـات العليا.

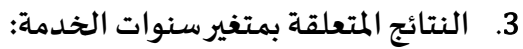

تم استخدام تحليل التباين الأحادي (One-way ANOVA)، للكشف عن دلالة الفروق في واقع التعليم المدمج من وجهاة نظر المعلمين بمديرية تربية قلقيلية في ضوء متغير الخدمة (أقل من 5 سنوات، من 5-10 سنوات، أكثر من 10 سنوات)، وكانت النتائج كما في جدول (8) (8). جدول (8): نتائج تحليل التباين الأحادي لفحص دلالة الفروق في و اقع التعليم المدمج تبعاً لمتغيرسنوات الخدمة

\begin{tabular}{|c|c|c|c|c|c|c|}
\hline الإحصلائية & قيمة (ف) & متوسط المربعات & درجات الحرية & مجموع المربعات & مصدر التباين & المجالات \\
\hline \multirow{3}{*}{0.112} & \multirow{3}{*}{2.226} & 1.198 & 2 & 2.396 & بين المجموعات & \multirow{3}{*}{ مفهوم التعليم } \\
\hline & & \multirow[t]{2}{*}{0.538} & 140 & 75.349 & داخل المجموعات & \\
\hline & & & 142 & 77.744 & المجموع & \\
\hline \multirow{3}{*}{0.578} & \multirow{3}{*}{0.550} & 0.342 & 2 & 0.684 & بين المجموعات & \multirow{3}{*}{ أهمية تطبيق المدمج } \\
\hline & & 0.622 & 140 & 87.014 & داخل المجموعات & \\
\hline & & & 142 & 87.698 & المجموع & \\
\hline \multirow{3}{*}{0.732} & \multirow{3}{*}{0.313} & 0.151 & 2 & 0.302 & بين المجموعات & \multirow{3}{*}{ متطلبات التعليم } \\
\hline & & 0.483 & 140 & 67.591 & داخل المججموعات & \\
\hline & & & 142 & 67.893 & المجموع & \\
\hline \multirow{3}{*}{0.946} & \multirow{3}{*}{0.055} & 0.016 & 2 & 0.032 & بين المجموعات & تحديات التعليم \\
\hline & & \multirow[t]{2}{*}{0.289} & 140 & 40.527 & داخل المجمموعات & \multirow[t]{2}{*}{ المدمجج } \\
\hline & & & 142 & 40.559 & المجموع & \\
\hline \multirow{3}{*}{0.489} & \multirow{3}{*}{0.720} & 0.209 & 2 & 0.417 & بين المجموعات & \multirow{3}{*}{ الدرجة الكلية } \\
\hline & & \multirow[t]{2}{*}{0.290} & 140 & 40.565 & داخل المججموعات & \\
\hline & & & 142 & 40.982 & المجموع & \\
\hline
\end{tabular}

يتضح من الجدول(8) عدم وجود فروق دالة إحصائياً عند مستوى الدلالة (م=0.05) بين واقع التعليم المدمج من وجهة نظر المعلمين بمديرية تربية قلقيلية تعزى لمتغير سنوات الخدمة، في مجالات مفهوم التعليم المدمج، وأهمية تطبيق التعليم المدمج، ومتطلبات التعليم المدمج، وتحديات

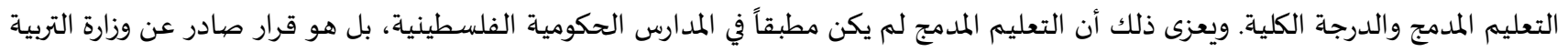
والتعليم الفلسطينية وذلك لاستمرارية التعليم الآمن في المدارس للطلبة في ظل جائحة كورونا، ولذلك فسنوات الخدمة ليس لها أثر في المعرفة،

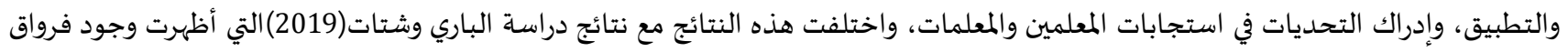

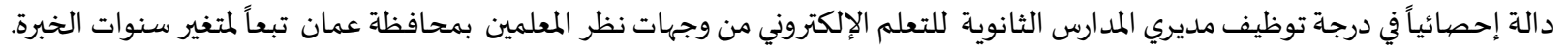

4 - النتائج المتعلقة بمتغير مجال التخصص:

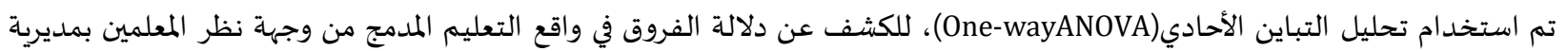
تربية قلقيلية في ضوء متغير التخصص (علمي، إنساني، مهني -صناعي)، وكانت النتائج كما في جدول (9). جدول (9): نتائج تحليل التباين الأحادي لفحص دلالة الفروق تبعاً لمتغير مجال التخصص

\begin{tabular}{|c|c|c|c|c|c|c|}
\hline الدلالة الإحصائية & قيمة(ف) & متوسط المربعات & درجات الحربة & مجموع المربعات & مصدر التباين & المجالات \\
\hline & & 1.221 & 2 & 2.442 & بين المجموعات & \\
\hline \multirow[t]{3}{*}{0.107} & 2.270 & 0.538 & 140 & 75.302 & داخل المجموعات & المعرفة بمفهوم التعليم \\
\hline & & & 142 & 77.744 & المجموع & المدمج \\
\hline & & 1.815 & 2 & 3.629 & بين المجموعات & \\
\hline \multirow[t]{3}{*}{0.052} & 3.022 & 0.600 & 140 & 84.068 & داخل المجموعات & أهمية تطبيق التعليم المدمج \\
\hline & & & 142 & 87.698 & المجموع & \\
\hline & & 0.962 & 2 & 1.923 & بين المجموعات & \\
\hline \multirow[t]{2}{*}{0.134} & 2.041 & 0.471 & 140 & 65.970 & داخل المجموعات & متطلبات التعليم المدميج \\
\hline & & & 142 & 67.893 & المجموع & \\
\hline 0.171 & 1.787 & 0.505 & 2 & 1.010 & بين المجموعات & تحديات التعليم المدمج \\
\hline
\end{tabular}




\begin{tabular}{|c|c|c|c|c|c|c|}
\hline & & \multirow[t]{2}{*}{0.282} & & & \multicolumn{2}{|l|}{ داخل المجموعات } \\
\hline & & & 142 & 40.559 & المجموع & \\
\hline \multirow{3}{*}{0.086} & & 0.705 & 2 & 1.410 & بين المجموعات & \multirow{3}{*}{ الدرجة الكلية } \\
\hline & 2.494 & 0.283 & 140 & 39.572 & داخل المجموعات & \\
\hline & & & 142 & 40.982 & المجموع & \\
\hline
\end{tabular}

يتضح من الجدول (9) عدم وجود فروق دالة إحصائياً عند مستوى الدلالة (Q=0.05) بين واقع التعليم المدمجي من وجهة نظر المعلمين بمديرية

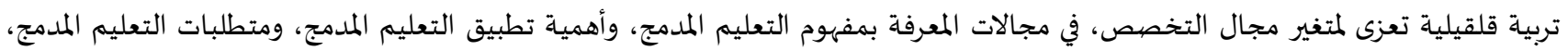

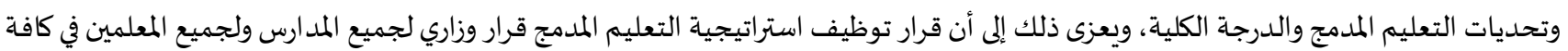

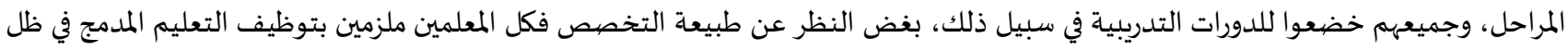

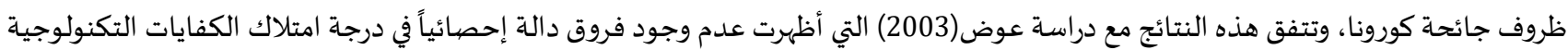
لأعضاء هيئة التدريس بالجامعات الأردنية تعزى لمتغير التخصص.

نتائج السؤال الثالث والذي ينص على "ما تحديات تطبيق التعليم المدمج من وجهة نظرمشرفي التربية والتعليم بمديرية تربية قلقيلية؟" تمت الإجابة على السؤال الثالث من خلال مقابلة خمسة من مشرفي التربية والتعليم بمديرية تربية قلقيلية، فكانت استجابتهم على السؤال

الثالث كما هو موضح في الجدول (10): الابل السوال

جدول (10): تحديات تطبيق التعليم المدمج من وجهة نظر مشرفي التربية والتعليم بمديرية تربية قلقيلية (ن=5)

\begin{tabular}{|c|c|c|c|c|c|c|c|}
\hline 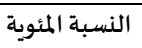 & 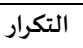 & م & م4 & م3 & ק & ק1 & 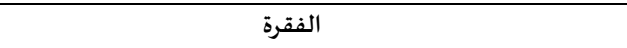 \\
\hline$\% 80$ & 4 & 1 & & 1 & 1 & 1 & عدم توفر الانترنت وأجهزة الحواسيب لدى أغلبية المعلمين وأولياء الأمور. \\
\hline$\% 40$ & 2 & & & 1 & & 1 & جهل معظم أولياء الأمور في التقنيات الحديثة والبرامج الموظفة في التعليم عن بعد. \\
\hline$\% 40$ & 2 & 1 & & & & 1 & عدم تمكن الأهالي من متابعة أبنائهم في نفس الوقت. \\
\hline$\% 40$ & 2 & & & & 1 & 1 & الثقافة العامة لدى المجتمع بعدم جدوى التعلم عن بعد وضرورة التعليم الوجاهي. \\
\hline$\% 40$ & 2 & 1 & 1 & & & & زيادة الأعباء على المعلمين، ومتابعة الطلبة وجاهياً وإلكترونياً. \\
\hline$\% 20$ & 1 & & & & 1 & & ضعف مهارات توظيف التكنولوجيا لدى بعض المعلمين، والحاجة لدورات تدرببية. \\
\hline
\end{tabular}

يتضح من الجدول (10) أن أعلى نسبة تكرار في استجابات مشرفي التربية والتعليم حول تحديات تطبيق التعليم المدمج كانت عدم توفر الانترنت

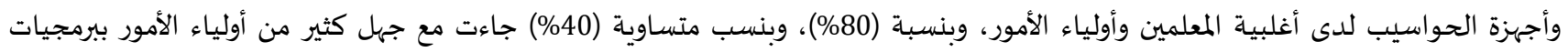

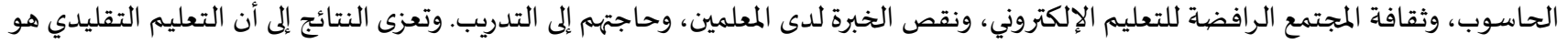

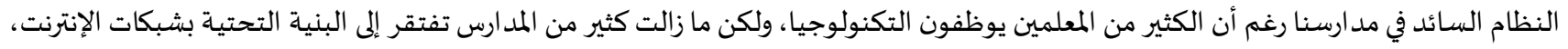

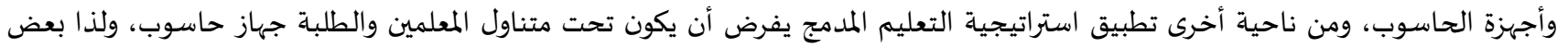

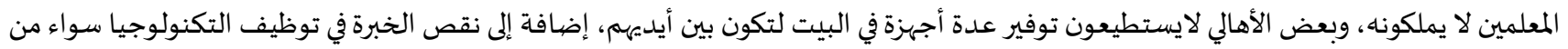

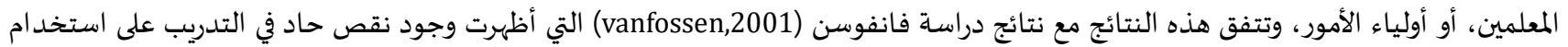

الانترنت، وتوظيفاه في الغرفة الصفية.

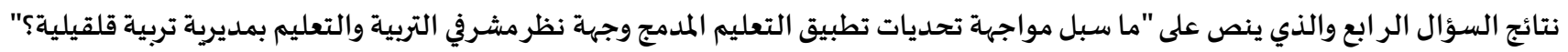

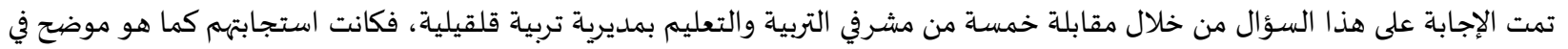

الجدول (11).

جدول (11): استجابات مشرفي التربية والتعليم المتعلقة بسبل مواجهة تحديات تطبيق التعليم المدمجج (ن=5)

\begin{tabular}{|c|c|c|c|c|c|c|c|}
\hline النسبة المئوية النسية & 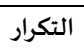 & ק & م4 & 3 & 2 & ק1 & الفقرة \\
\hline$\% 80$ & 4 & 1 & 1 & & 1 & 1 & تزويد المعلمين والطلبة بأجهزة حاسوب. \\
\hline$\% 60$ & & & & 1 & 1 & 1 & تفعيل المنصات التعليمية وقناة التلفاز التعليمية من (1-4) \\
\hline$\% 40$ & & 1 & & 1 & & & تدريب المعلمين على البرامج التعليمية الإلكترونية \\
\hline$\% 40$ & & 1 & & 1 & & & تغيير قناعات الأهالي نحو التعليم الإلكتروني. \\
\hline$\% 20$ & & & 1 & & & & التنسيق مع شركات الاتصالات، والإنترنت، والمؤسسات الداعمة \\
\hline$\% 20$ & & & & & 1 & & ت توفير خدمة الإنترنت المجاني للطلبة. \\
\hline$\% 20$ & & & 1 & & & & التركيز على المعارف والمهارات الأساسية في التعليم الوجاهي. \\
\hline
\end{tabular}


يتضح من الجدول(11) أن (80\%) من استجابات مشرفي التربية والتعليم جاءت مع ضرورة تزويد المعلمين والطلبة بأجهزة الحاسوب، و(60\%)

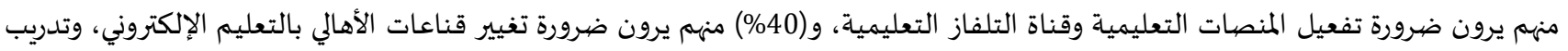
المعلمين والطلبة، و(20\%) ضرورة التنيسق مع الشركات الداعمة والمزودة للإتصالات، وتوفير خدمة إنترنت مجانية، والتركيز على المعارف والمهارات

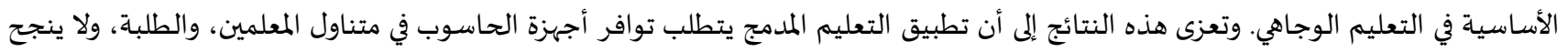
التعليم المدمج بدونها، كما أنَّ هناك تخوف من فشله لذاي هذا ارتأى المشرفين أنها من المناسب توفير منصيات تعليمية وقنوات تلفزيونية تعليمية متاحة

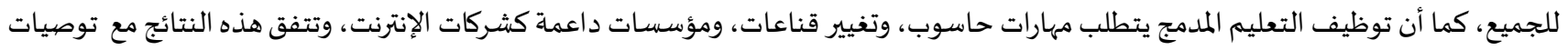
دراسة الحجايا (2013) التي أوصت الدراسة بزيادة الدعم المقدم للجامعات لرفع مستوى البنية التحتية للتعليم الإلكتروني في الجامعات الأردنية.

$$
\text { فوصيات الدراسة: }
$$
1. العمل على مواجهة تحديات التعليم المدمج من قبل القائمين على العملية التربوية في وزارة التربية والتعليم.

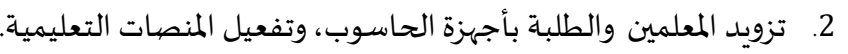
3. العمل على تطوير خبرات المعلمين بالتعليم المدمج من خلال إلحاقهم بدورات تدريبية حول البرامج التعليمية الإلكترونية.

مقترحات الدراسـة: 1. توفير مراكز لصيانة أجهزة الحاسوب الخاصة بالمعلمين والطلبة بأسعار رمزية من خلال تنسيق الوزارة مع المختصين في هذ المجال.

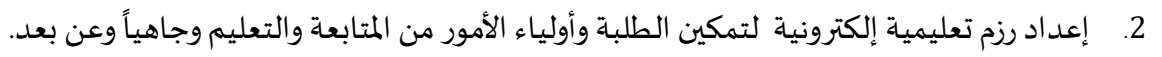
3. إجراء دراسات بحثية مشابهة في مديريات مختلفة من فلسطين.

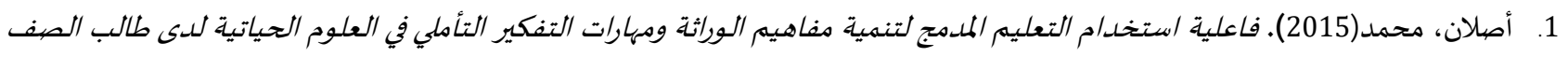

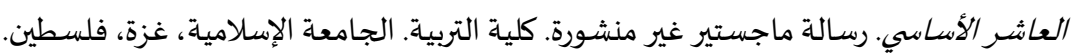

2.

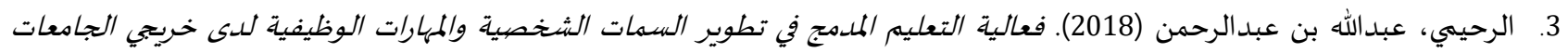
السعودية من وجهات نظر ملديري العمل والطلبة أنضسهم: الجامعة الإكترونية السعودية أنمونجا. مؤتة للبحوث والدراسات، سلسلة العلوم الإنسانية والاجتماعية: 33(4): 209-238. 4. شديفات، يحيى(2007). أثر استخدام الأنترنت في تحصيل طلبة مساق التخطيط التويوي في جامعة أل الببيت. المجلة الأردنية في العلوم التربوية:

5. الشهري، بندر عبد الله(2008). تقويم مستوى أداء أعضياء هيئة التدريس التعليمي في بيئة التعليم الاكتروني بالجامعة العببية السعودية. رسالة ماجستير غير منشورة. جامعة الملك سعود، الرياض. المملكة العربية السعودية.

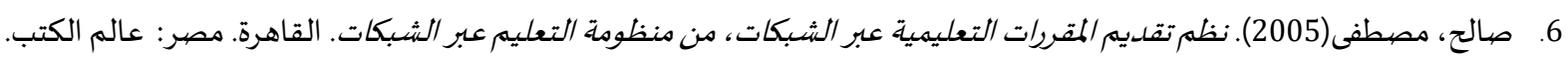

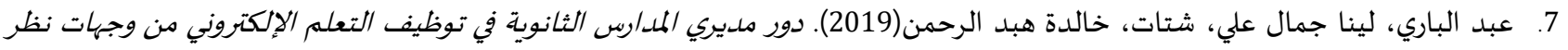

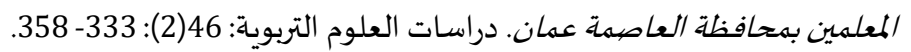
8. عبد العاطي، حسن، الباتع محمد، وأبو خطوة، السيد عبد المولى (2009). التعلم الإلكتروني الرقهي (النظرية-التصميم-الإنتاج). الإسكندرية. مصر: دار الجامعة الجديدة. 9. العنزي، عبد الله شطيط عايد (2019). واقع استخدام معلمي الممحلة الثانوية بلدولة الكويت للتعلم الملدمج من وجهات نظر المعلمين والملدراء. رسالة ماجستير. جامعة ال البيت كلية العلوم التربوية. عمان، الأردن.

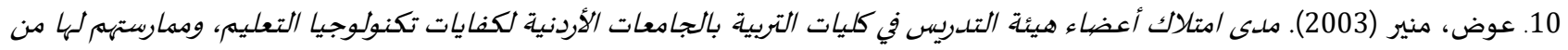
وجهة نظرهم. رسالة ماجستير غير منشورة. جامعة اليرموك. الأردن.

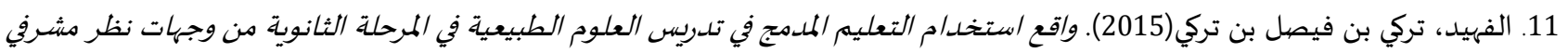
ومعلمي العلوم بمنطقة القصيم. رسالة ماجستير غير منشورة. جامعة أم القرى. مكاة المكرمة. المملكة العربية السعودية. 
12. القباني، نجوان حامد عبد الواحد (2017). أثر مستويات الدمج في التعلم الممدمج على تنمية مهارات تصعيم خرائط المفاهيم الرقمية لدى طلاب

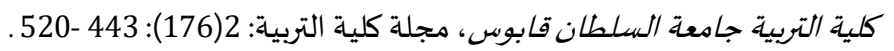

13. هلال، إسلام طه حسين (2019). فعالية بزنامج تعليهي باستخدام التعلم الممدمج على مستوى أداء بعض المهارات المات الأساسية للمبتدئين في كرة

القدم. المجلة العلمية للبحوث والدراسات في التربية: جامعة بورسعيد -كلية التربية الرياضية. بور سعيد. مصر. (37): 24-46.

ثانياً: المراجع الأجنبية:

1. Dewantara, D.,Misbah, M.,\& Wati, M.(2020). The implementation of blended learning in analog electronic learning. Journal of Physics: Conference Series, 1422 (1): 012002, https://doi.org/10.1088/1742-6596/1422/1/012002.

2. Dewantara, Misbah Mumtaz (2020). Blended Learning to Improve Learning Outcomes in Digital Electronics Courses Conference Paper (PDF Available).

3. Kumar, A. (2016). Student Perspective on Blended Learning in Higher Education. INTERNATIONAL JOURNAL OF INNOVATIVE RESEARCH \& DEVELOPMENT Education, 5(2). Pp231-238

4. Merc,A. (2015). Using technology in the Classroom: A Study with Turkish Pre- service EFL Teachers. Turkish online journal of Educational Technology, TOJET, 14(2): 229-240.

5. Schmid, A., Melzer, P., \& Schoop, M. (2020). Gamifying Electronic Negotiation Training - A Mixed Method Study of Students' Motivation, Engagement and Learning. In ECIS. https://www.aisel.ais.

6. Smith, Tara. (2016). New Frontiers in Blended learning www.Techlearning.com.

7. Vanafossen, N. (2001). Competency of Using the Internet in the Classroom. Educational Technology, 32(19): 65-66. 


\title{
The reality of blended education from the teachers' point of view in the Qalqilya education directorate in light of some variables
}

\author{
1Soha Jallad, ${ }^{2}$ Abeer Qashou', ' 2 Lina Abu Hamad, 4Bara'a Juaidi
}

1,2,3,4Educational Administration, An-Najah National University, Palestine

1Sohajallad8@gmail.com, 2abeer.qashoo7@gmail.com, 33ina.rabaya11@yahoo.com, 4barahayazeed@gmail.com

Received : 30/9/2020 Revised : 9/10/2020 Accepted : 22/10/2020 DOI : https://doi.org/10.31559/EPS2021.9.3.2

Abstract: The study aimed to identify the reality of blended education from the teachers' point of view in the Qalqilya Education Directorate in light of some variables, and to identify the challenges of blended education from the viewpoint of the education supervisors of the Qalqilya Education Directorate and ways to confront them. The study tool consisted of a questionnaire consisting of (33) items, distributed on (4) axes, which were applied to (143) teachers, in addition to conducting qualitative interviews with (5) education supervisors in the Qalqilya Education Directorate. The results of the study showed that the degree the faculty for the reality of blended education from the teachers' point of view in the Qalqilya Education Directorate was large, with an arithmetic average (3.84), and a percentage (\%75.8), The field of blended learning challenges ranked first with an arithmetic average (4.31) and a percentage (\%86.2). Compact in the second rank with an arithmetic average (3.82) and a percentage (\%76.4) and the area of knowledge of the concept of blended learning came in the third rank, with an arithmetic average (3.69) and a percentage (\%73.8), and the importance of applying blended education ranked fourth with an average Arithmetic (3.55) and a percentage (\%71), The results also showed that there are statistically significant differences on the total degree of the reality of blended education from the teachers' point of view due to the gender variable and in favor of males, and the presence of statistically significant differences on the total degree of the reality of blended education due to the scientific qualification variable In favor of the master's degree, while the results did not reveal any statistically significant differences attributed to the variables of years of service and field of specialization, and the results of the educational supervisors' interviews showed that (\%80) of the challenges of applying blended education relate to the lack of computers between the reach of teachers and students, and that (\%80) One of the ways to face the challenges of implementing blended education is related to providing teachers and students with computers and tablets, and the study recommended working to meet the challenges of blended learning by those in charge of the educational process in the Ministry of Education, providing teachers and students with computers, activating educational platforms, and working to develop expertise Teachers are enrolled in blended education by enrolling them in training courses on e-learning programs. The study suggested providing centers for the maintenance of teachers 'and students' computers at prices It is symbolic through the Ministry's coordination with specialists in this field, preparing electronic educational packages to enable students and parents to follow-up and education face-to-face and remotely, and to conduct similar research studies in different directorates of Palestine.

Key words: Blended Learning; Blended Learning Challenges; Qalqilya. 


\section{References:}

1. 'bd Al'aty, Hsn, Albat' Mhmd, Wabw Khtwh, Alsyd 'bd Almwla (2009). Alt'lm Alelktrwny Alrqmy (Alnzryh-AltsmymAlentaj). Aleskndryh. Msr: Dar Aljam'h Aljdydh.

2. Al'nzy, 'bd Allh Shtyt 'ayd (2019). Waq' Astkhdam M'lmy Almrhlh Althanwyh Bdwlt Alkwyt Llt'lm Almdmj Mn Wjhat Nzr Alm'lmyn Walmdra'. Rsalt Majstyr. Jam't Al Albyt Klyt Al'lwm Altrbwyh. 'man, Alardn.

3. 'bd Albary, Lyna Jmal 'ly, Shtat, Khaldh Hbd Alrhmn (2019). Dwr Mdyry Almdars Althanwyh Fy Twzyf Alt'lm Alelktrwny Mn Wjhat Nzr Alm'Imyn Bmhafzt Al'asmh 'man. Drasat Al'lwm Altrbwyh: 46(2): 333- 358.

4. 'wd, Mnyr (2003). Mda Amtlak A'da' Hy't Altdrys Fy Klyat Altrbyh Baljam'at Alardnyh Lkfayat Tknwlwjya Alt'lym, Wmmarsthm Lha Mn Wjht Nzrhm. Rsalt Majstyr Ghyr Mnshwrh. Jam't Alyrmwk. Alardn.

5. Aslan, Mhmd (2015). Fa'lyt Astkhdam Alt'lym Almdmj Ltnmyh Mfahym Alwrathh Wmharat Altfkyr Altamly Fy Al'lwm Alhyatyh Lda Talb Alsf Al'ashr Alasasy. Rsalt Majstyr Ghyr Mnshwrh. Klyt Altrbyh. Aljam'h Aleslamyh, Ghzh, Flstyn.

6. Alfhyd, Trky Bn Fysl Bn Trky(2015). Waq' Astkhdam Alt'elym Almdmj Fy Tdrys Al'lwm Altby'yh Fy Almrhlh Althanwyh Mn Wjhat Nzr Mshrfy Wm'lmy Al'lwm Bmntqh Alqsym. Rsalt Majstyr Ghyr Mnshwrh. Jam't Am Alqra. Mkh Almkrmh. Almmlkh Al'rbyh Als'wdyh.

7. Hlal, Eslam Th Hsyn (2019). F'alyt Brnamj T'lymy Bastkhdam Alt'lm Almdmj 'la Mstwa Ada' B'd Almharat Alasasyh Llmbtd'yn Fy krt Alqdm. Almjlh Al'lmyh Llbhwth Waldrasat Fy Altrbyh: Jam't Bwrs'yd -Klyt Altrbyh Alryadyh. Bwr S'yd. Msr. (37): 24-46.

8. Alhjaya, Nayl (2013). Waq' Alt'lym Alalktrwny Fy Aljam'at Alardnyh. Almjlh Altrbwyh Aldwlyh Almtkhssh: 2(2): 140151.

9. Alqbany, Njwan Hamd 'bd Alwahd (2017). Athr Mstwyat Aldmj Fy Alt'lm Almdmj 'la Tnmyt Mharat Tsmym Khra't Almfahym Alrqmyh Lda Tlab Klyt Altrbyh Jam't Alsltan Qabws, Mjlt Klyt Altrbyh: 2(176): 443-520.

10. Alrhymy, 'bdallh Bn 'bdalrhmn (2018). F'alyt Alt'lym Almdmj Fy Ttwyr Alsmat Alshkhsyh Walmharat Alwzyfyh Lda Khryjy Aljam'at Als'wdyh Mn Wjhat Nzr Mdyry Al'ml Waltlbh Anfshm: Aljam'h Alelktrwnyh Als'wdyh Anmwdja. M'th Llbhwth Waldrasat, Slslt Al'lwm Alensanyh Walajtma'yh: 33(4): 209-238.

11. Salh, Mstfa (2005). Nzm Tqdym Almqrrat Alt'lymyh 'br Alshbkat, Mn Mnzwmh Alt'lym 'br Alshbkat. Alqahrh. Msr: 'alm Alktb.

12. Shdyfat, Yhya (2007). Athr Astkhdam Alantrnt Fy Thsyl Tlbt Msaq Altkhtyt Altrbwy Fy Jam't Al Albyt. Almjlh Alardnyh Fy Al'lwm Altrbwyh: 3(1): 1-3.

13. Alshhry, Bndr 'bd Allh (2008). Tqwym Mstwa Ada' A'da' Hy't Altdrys Alt'lymy Fy By't Alt'lym Alaktrwny Baljam'h Al'rbyh Als'wdyh. Rsalt Majstyr Ghyr Mnshwrh. Jam't Almlk S'wd, Alryad. Almmlkh Al'rbyh Als'wdyh. 


\section{ملحق (1)}

الاستبانة ملجية

حضرة المعلم المحترم/ المعلمة المحترمة تحية طيبة وبعد:

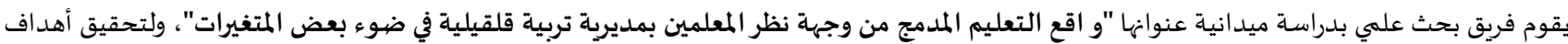

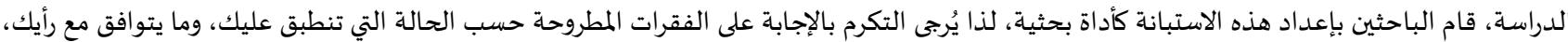
علماً بأن البيانات الواردة ستُستخدم لأغراض البحث البند العلمي فقط.

شاكرين لكم حُسن تعاونكم

القسيم الأول:

أولاً: البيانات الشخصية

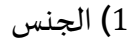

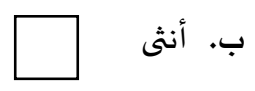

ج. ماجستير فأعلى ل<smiles>C[As][AsH2][AsH2]</smiles>
ب. من 5 -10سنوات

ج. أكثر من 10سنوات<smiles>C1CCC1</smiles>
4) مجال التخصص مل سنوات
1. - ا. ذكر 2) المؤهل العلهي ا.دبلوم الموهل العبن 3) سنوات الخدمة ا. أقل من 5 سنوات ات التومات ا. علمي

يُرجى وضع إشـارة (ل) في المكان المناسب من وجهاة نظرك

\begin{tabular}{|c|c|c|c|c|c|c|}
\hline معارض & معارض & محايد & أوافق & بشدة & 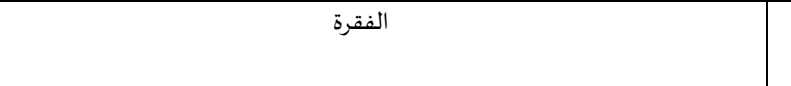 & 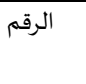 \\
\hline \multicolumn{7}{|c|}{ المجال الأول: المعرفة بمفهوم التعليم المدمج } \\
\hline & & & & & يمزج التعليم المدمج بين التعلم الإلكتروني والتعلم الصيفي. & 1 \\
\hline & & & & & يوظف التعلم الإلكتروني أدوات التعلم الإلكتروني وشبكة الإنترنت. & 2 \\
\hline & & & & & يتلقى الطالب من خلال التعلم المدمج تعليمه جزئياً من خلال الإنترنت. & 3 \\
\hline & & & & & يُّمكن المعلمين من اختيار طريقة التعلم التقليدي أو الإلكتروني حسب الموقف التعليمي. & 4 \\
\hline & & & & & يتيح التعلم المدمج للمتعلم التحكم بالوقت والمكان ومسار التعلم. & 5 \\
\hline \multicolumn{7}{|c|}{ المجال الثاني: أهمية تطبيق التعليم المدمج } \\
\hline & & & & & يُمكن المتعلمين من متابعة تعليميهم إلكترونيا في حال التغيب عن المدرسة. & 6 \\
\hline & & & & & يثري حلقات النقاش والحوار بين المعلمين والمشرفين عبر برامج إلكترونية. & 7 \\
\hline & & & & & يمنح المتعلمين القدرة على التعلم الذاتي. & 8 \\
\hline & & & & & يحقق للمتعلمين المرونة في التعلم والاستقلالية في التعليم. & 9 \\
\hline & & & & & يطور التعليم المدمج مهاراتهم في تكنولوجيا المعلومات. & 10 \\
\hline & & & & & يمكن التعليم المدمج من تجاوز الحدود المكانية، والظروف التي تعيق عملية التعلم. & 11 \\
\hline & & & & & يتيح التعليم المدمج أمام المعلمين لإقامة منصات تعليمية On Line بأقل تكلفة . & 12 \\
\hline & & & & & يعزز الجوانب الإنسانية بين المعلمين والمتعلمين. & 13 \\
\hline \multicolumn{7}{|c|}{ المجال الثالث: متطلبات التعليم المدمج } \\
\hline & & & & & تزويد الغرف الصفية بجاز حاسوب متصل بشبكة الإنترنت. & 14 \\
\hline & & & & & إعداد مقرر إلكتروني لكل مادة تعليمية. & 15 \\
\hline & & & & & تدريب المعلمين وأولياء الأمور على كيفية استخدام البرامج الإلكترونية وتفعيلها. & 16 \\
\hline & & & & & توفير مواقع التحاور الإلكتروني مع المشرفين وأولياء الأمور. . & 17 \\
\hline & & & & & المقدرة على التدربس بالطريقة التقليدية والتطبيق إلكترونياً. & 18 \\
\hline
\end{tabular}




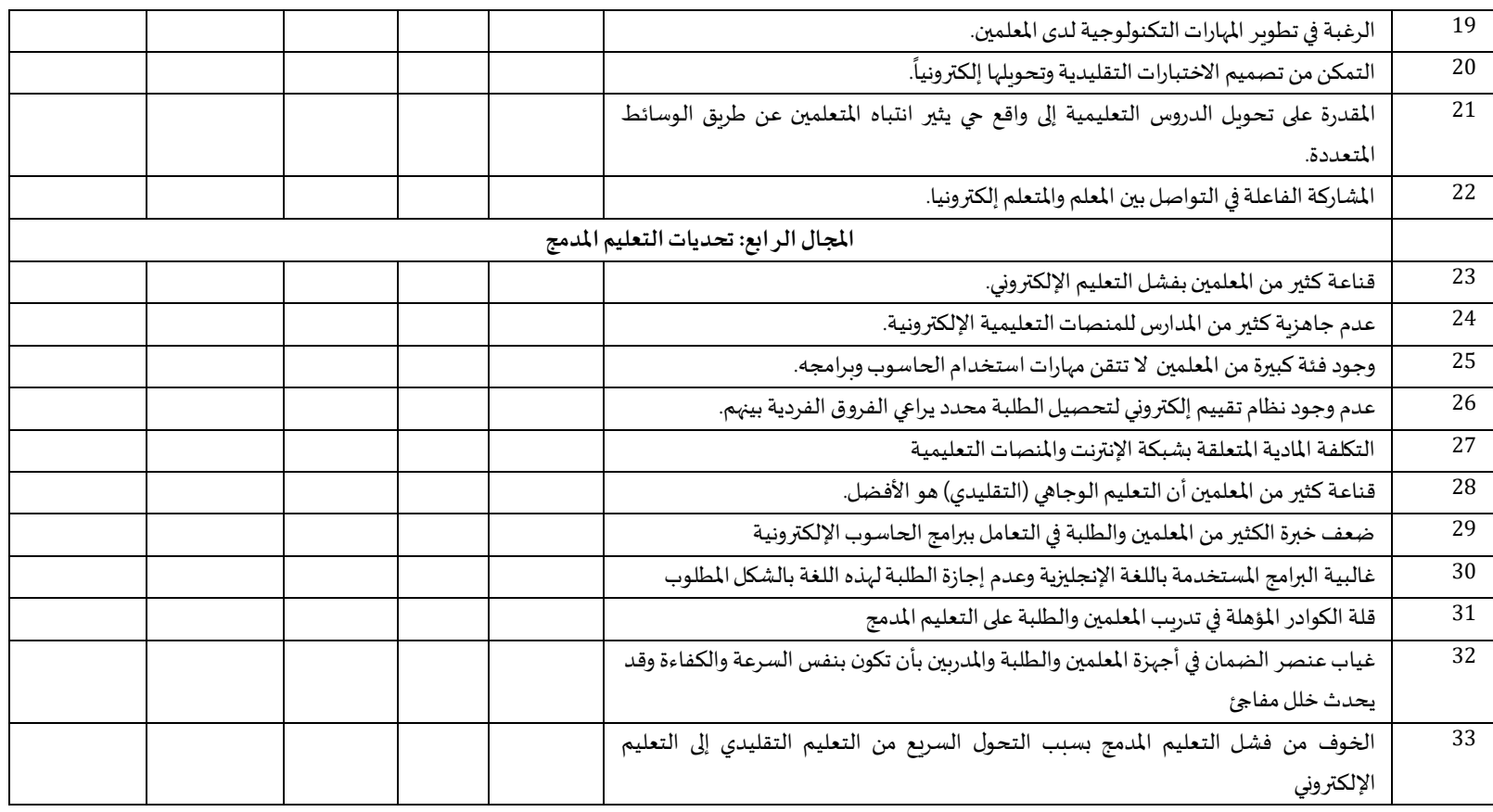

